\title{
Mechanical Overloading Increases Maximal Force and Reduces Fragility in Hind Limb Skeletal Muscle from Mdx Mouse
}

\author{
Arnaud Ferry, ${ }^{* \dagger}$ Ara Parlakian,,${ }^{\ddagger}$ Pierre Joanne, ${ }^{\ddagger}$ Bodvael Fraysse, ${ }^{*}$ Takouhie Mgrditchian, ${ }^{* \ddagger}$ Pauline Roy, ${ }^{*}$ Denis Furling, ${ }^{*}$ \\ Gillian Butler-Browne, ${ }^{*}$ and Onnik Agbulut ${ }^{\ddagger}$
}

From the Myology Research Center, * UM76 INSERM U974, Centre National de la recherche scientifique FRE 3617, Institut de Myologie, University of Pierre et Marie Curie-Paris 6, Sorbonne Universités, Paris; the University of Paris Descartes, ${ }^{\dagger}$ Sorbonne Paris Cité, Paris; and the Biological Adaptation and Aging, ${ }^{\ddagger}$ Institut de Biologie Paris-Seine, Centre National de la Recherche Scientifique UMR 8256, Université Pierre et Marie Curie-Paris 6, Sorbonne Universités, Paris, France

Accepted for publication March 9, 2015.

Address correspondence to Arnaud Ferry, Ph.D., G.H. Pitié-Salpétrière, Bâtiment Babinski, INSERM U974, 47 blvd de l'Hôpital, 75651 Paris Cedex 13, France. E-mail: arnaud.ferry@upmc.fr.

\begin{abstract}
There is fear that mechanical overloading (OVL; ie, high-force contractions) accelerates Duchenne muscular dystrophy. Herein, we determined whether short-term OVL combined with wheel running, shortterm OVL combined with irradiation, and long-term OVL are detrimental for hind limb mdx mouse muscle, a murine model of Duchene muscular dystrophy exhibiting milder dystrophic features. OVL was induced by the surgical ablation of the synergic muscles of the plantaris muscle, a fast muscle susceptible to contraction-induced muscle damage in $\mathrm{mdx}$ mice. We found that short-term OVL combined with wheel and long-term OVL did not worsen the deficit in specific maximal force (ie, absolute maximal force normalized to muscle size) and histological markers of muscle damage (percentage of regenerating fibers and fibrosis) in $\mathrm{mdx}$ mice. Moreover, long-term OVL did not increase the alteration in calcium homeostasis and did not deplete muscle cell progenitors expressing Pax 7 in $\mathrm{mdx}$ mice. Irradiation before short-term $\mathrm{OVL}$, which is believed to inhibit muscle regeneration, was not more detrimental to $\mathrm{mdx}$ than control mice. Interestingly, short-term OVL combined with wheel and long-term OVL markedly improved the susceptibility to contraction-induced damage, increased absolute maximal force, induced hypertrophy, and promoted a slower, more oxidative phenotype. Together, these findings indicate that OVL is beneficial to $\mathrm{mdx}$ muscle, and muscle regeneration does not mask the potentially detrimental effect of OVL. (Am J Pathol 2015, 185: 2012-2024; http://dx.doi.org/10.1016/j.ajpath.2015.03.027)
\end{abstract}

Dystrophin plays a role in force transmission, sarcolemmal stability and localization, and function of different proteins that initiate a muscle damage process in its absence. ${ }^{1-3}$ The deficiency in dystrophy causes Duchenne muscular dystrophy (DMD), a severe muscle wasting in all skeletal muscles combined with cardiomyopathy.

The mdx mouse, a milder murine model of DMD, exhibits several dystrophic features in hind limb muscle. There is a loss of force-generation capacity in the dystrophin-deficient mdx muscle compared with control muscle. Indeed, the murine dystrophin-deficient muscle exhibits a reduced specific maximal force [ie, the absolute maximal force generated relative to muscle size (cross-sectional area or weight)]. ${ }^{4-7}$ Mdx muscle is also more fragile [ie, susceptible to damage caused by the acute effect of few contractions, especially lengthening (eccentric) contractions producing high forces]. In fact, few lengthening contractions cause an immediate marked reduction in force generation in fast-twitch $\mathrm{mdx}$ muscle. ${ }^{8,9} \mathrm{Mdx}$ muscle also exhibits regenerating fibers, which are centronucleated, and expressed neonatal (nn) isoform of myosin heavy chain-nn, indicating that the absence of dystrophin causes repeated cycles of degeneration and regeneration. Several studies have reported that calcium

Supported by Université Pierre et Marie Curie (A.F., D.F., G.B.B., O.A.), National Scientific Research Center-France (A.F., D.F., G.B., O.A.), INSERM (A.F., D.F., G.B.B.), University Paris Descartes (A.F.), and the Association Française contre les Myopathies grant number 16605 (A.F., D.F., G.B.B.).

Disclosures: None declared. 
homeostasis is also altered in mdx muscle. ${ }^{10-13}$ For example, cytosolic calcium content is increased in mdx mice. ${ }^{10-12}$ The physiopathological processes causing these dystrophic features are not well known, but a widely accepted hypothesis is that calcium homeostasis plays a central role in the physiopathology. ${ }^{13}$

Resistance training uses high-force contractions to improve physical performance in healthy subject and combats weakness and atrophy in the cases of disuse and aging. However, studies are needed to determine whether resistance training could also be used to improve the dystrophic phenotype and to confirm that it would not induce muscle damage. ${ }^{14,15}$ Because of the susceptibility of contraction-induced damage, the risk that exercise training using high-force contractions accelerates the muscular dystrophy has been debated. ${ }^{14-16}$ In a recent study, we reported that short-term mechanical overloading (OVL), a model of resistance training, did not worsen dystrophic features because the deficit in maximal specific force and the percentage of centronucleated fibers, a histological marker of muscle damage, were not increased in response to OVL in mdx mice. ${ }^{17}$ However, we do not yet know whether it worsens the susceptibility to contraction-induced damage. Moreover, there is a possibility that long-term OVL would aggravate the disease, ${ }^{18}$ plausibly because muscle cell progenitors are depleted, or loses its function in a dystrophic environment, resulting in an imperfect muscle repair. OVL that increases both neural activity and loading ${ }^{19-23}$ mimics intensive resistance training, which has been shown to increase absolute maximal force production in animal models by $22 \%$ to $37 \%,{ }^{24-26}$ whereas OVL induces a threefold higher increase in mice (80\% to $97 \%) .{ }^{17,23} \mathrm{OVL}$ also triggers several cellular and molecular adaptations, such as hypertrophy in the skeletal muscle. This aspect of muscle remodeling induced by OVL results from increased fiber diameter and total number of fibers per cross section. ${ }^{17,22,27-29}$ The promotion of a slower and/or oxidative fiber phenotype is an another important cellular and molecular muscle adaptation in response to OVL. ${ }^{17,22,29-31}$

Our aim was to determine whether repeated high-force contractions, as would be induced by OVL, would be detrimental for the $\mathrm{mdx}$ plantaris muscle, a fast muscle susceptible to contraction-induced damage. We analyzed maximal specific force, immediate susceptibility to contraction-induced damage, histological markers of muscle damage (regenerating fibers and fibrosis), alteration in calcium homeostasis (resting calcium content), and functional, cellular, and molecular adaptations (gain in maximal force, hypertrophy, and fiber-type transition) in response to OVL. Our general hypothesis was that if repeated high-force contractions would be detrimental, then dystrophic features would be worsened, and functional, cellular, and molecular adaptations in response to OVL would be impaired. More specifically, our first objective was to determine the effect of short-term (1 month) OVL combined with wheel running $(\mathrm{OVL}+$ wheel) in mdx mice. OVL is combined with wheel running to increase the use of the overloaded muscle (ie, the level of mechanical stress produced by normal cage activity). The second objective was to examine the effect of long-term OVL
(6 months) in mdx mice. In a previous study, we observed that short-term OVL was not detrimental, ${ }^{17}$ but it is possible that the duration was too short to exhaust the muscle repair capacity, because of depletion or loss of function of adult muscle cell progenitors (satellite cells). Our third objective was to determine whether OVL combined with prior irradiation would be more detrimental in $\mathrm{mdx}$ mice than in control mice. It is possible that regeneration of fibers may efficiently repair the potential damage induced by OVL in mdx mice. Because muscle regeneration could mask the potential deleterious effect of OVL, muscles from mdx mice were irradiated before OVL; irradiation will destroy satellite cells that are essential for muscle regeneration. ${ }^{32}$

\section{Materials and Methods}

\section{Animals and Treatments}

All procedures were performed in accordance with national and European legislations, under the license 75-1102 from the French government. Mdx mice and age- and sex-matched wildtype (C57BL/10) mice (referred to below as C57 mice) were 2 to 3 months of age at the beginning of the experiments. For mechanical OVL, mice were i.p. anesthetized with $50 \mathrm{mg} / \mathrm{kg}$ body weight pentobarbital. The plantaris muscles of both legs were mechanically OVL for 1 and 6 months by surgical removal of soleus muscles and a major portion of the gastrocnemius muscles, as described. ${ }^{17}$ Some overloaded mdx mice were placed in separate cages containing a wheel and were allowed to run 1 month ad libitum (referred to below as $\mathrm{mdx}+\mathrm{OVL}+$ wheel mice). Local irradiation (18 Gy) was performed using an X-ray irradiator to prevent muscle regeneration, by inhibiting the proliferation of muscle cell progenitors. ${ }^{33}$ The left hind limbs from some mice were $\gamma$-irradiated $(0.91 \mathrm{~Gy}$ per minute $\times 20$ minutes), before the surgical removal of soleus and gastrocnemius complex (referred to below as $\mathrm{mdx}+$ OVL+irr mice). The irradiated mice were studied after 1-month OVL. In some experiments, to analyze muscle calcium, extensor digitorum longus (EDL) muscles of both legs were mechanically overloaded for 5 to 6 months by the surgical removal of two thirds of distal tibialis anterior muscles. ${ }^{18,34,35}$

\section{Muscle Force and Susceptibility to Contraction- Induced Damage}

Maximal forces of plantaris muscles were evaluated by measuring in situ isometric force, as described previously. ${ }^{17}$ Mice were anesthetized (i.p., pentobarbital sodium, $50 \mathrm{mg} /$ $\mathrm{kg}$ ). During physiological experiments, supplemental doses were given as required to maintain deep anesthesia. The knee and foot were fixed with clamps and stainless steel pins. Plantaris muscles were exposed, and the distal tendons of the gastrocnemius and soleus muscle complex were cut. The distal tendons of plantaris muscles were attached to a dual mode servomotor (Aurora Scientific, Aurora, ON, Canada). Sciatic nerves were proximally crushed and distally stimulated using a bipolar silver electrode with supramaximal square wave pulses 
of 0.1-millisecond duration. Responses to tetanic stimulation (pulse frequency, 75 to $143 \mathrm{~Hz}$ ) were successively recorded. At least 1 minute was allowed between contractions. Absolute maximal force was determined at optimal length (length at which maximal tension was obtained during the tetanus). Force was normalized to the muscle weight as an estimate of specific maximal forces. Susceptibility to contraction-induced injury of mdx mice was then estimated from the force decrease resulting from lengthening contraction-induced injury. The sciatic nerves from mdx mice were stimulated for 700 milliseconds (frequency, $150 \mathrm{~Hz}$ ). A maximal isometric contraction of the plantaris muscle was initiated during the first 500 milliseconds. Then, muscle lengthening (10\% optimal length) at a velocity of $5.5 \mathrm{~mm}$ per second was imposed during the last 200 milliseconds. ${ }^{36,37}$ All isometric contractions were made at an initial length. Nine lengthening contractions of the muscle were performed, each separated by a 45 -second rest period. Maximal isometric force was measured 45 seconds after each lengthening contraction and expressed as a percentage of the initial maximal force. Some mdx mice also performed nine isometric contractions, in which muscle length was not increased. Body temperature was maintained at $37^{\circ} \mathrm{C}$ using radiant heat. After contractile measurements, the mice were euthanized with an overdose of pentobarbital, and muscles were weighed.

\section{Calcium Content}

EDL muscles overloaded for 5 to 6 months were pinned in SYLGARD-coated dishes containing normal physiological solution $[148 \mathrm{mmol} / \mathrm{L} \mathrm{NaCl}, 4.5 \mathrm{mmol} / \mathrm{L} \mathrm{KCl}, 2.5 \mathrm{mmol} / \mathrm{L}$ $\mathrm{CaCl}_{2}, 1 \mathrm{mmol} / \mathrm{L} \mathrm{MgCl} 2,10 \mathrm{mmol} / \mathrm{L} \mathrm{HEPES}$, and $5.5 \mathrm{mmol} / \mathrm{L}$ glucose (pH 7.4)]. Small bundles of 10 to 15 fibers, arranged in a single layer, were dissected lengthwise, tendon to tendon, with the use of microscissors. Muscle preparations were loaded for 1 hour with $3 \mu \mathrm{mol} / \mathrm{L}$ of the fura- $\mathrm{AM}$ fluorescent calcium probe (Molecular Probes, Life Technologies, Eugene, OR). All experiments were conducted at room temperature. Ratiometric Fura-2 fluorescence measurements were made using optical excitation filters of 380 and $360 \mathrm{~nm}$ and an IonOptix microStepper Switch integrated system (IonOptix LLC, Milton, MA). Emitted fluorescence $(510 \mathrm{~nm})$ was background subtracted. Cytosolic calcium concentration was calculated at rest, according to a modified method from Fraysse et al. ${ }^{38}$ A pseudoratiometric approach was used to measure calcium content. Fura-2 fluorescence was first recorded at $1000 \mathrm{~Hz}$ under 380$\mathrm{nm}$ excitation. Thereafter, Fura-2 fluorescence was recorded at $360 \mathrm{~nm}$. The 10 records were averaged at each excitation wavelength. Finally, the calcium content was calculated by calculating the ratio of the means (360:380) and transformed in calcium concentration values using the method described for resting cytosolic calcium concentration determination.

\section{Histology}

Transverse serial sections ( $8 \mu \mathrm{m}$ thick) of plantaris muscles (collected 1 and 6 months after OVL) were obtained using a cryostat, in the midbelly region. Some of sections were processed for histological analysis, according to standard protocols (stained for hematoxylin and eosin and Sirius red). ${ }^{17}$ Others were used for immunohistochemistry, as described previously. ${ }^{39}$ For determination of muscle fiber diameter and myosin heavy chain analysis, frozen unfixed sections were blocked for 1 hour in phosphate-buffered saline plus $2 \%$ bovine serum albumin and $2 \%$ sheep serum and incubated for 30 minutes with mouse Fab (Jackson ImmunoResearch Europe Ltd., Newmarket, UK) 1:100 in phosphate-buffered saline. Sections were then incubated overnight with primary antibodies against laminin (rabbit polyclonal, 1:300; Dako, Les Ulis, France) and myosin heavy chain isoforms (Developmental Studies Hybridoma Bank, University of Iowa, Iowa City, IA). After washes in phosphate-buffered saline, sections were incubated for 1 hour with secondary antibodies (Alexa Fluor; Life Technologies, Saint Aubin, France). To evaluate regenerating muscle fibers and the presence of satellite cells, unfixed sections were incubated with primary antibodies against myosin heavy chain isoform neonatal ${ }^{40}$ or Pax-7 (mouse monoclonal, 1:50; Santa Cruz Biotechnology, Heidelberg, Germany), respectively. For morphometric analyses, images were captured using a motorized confocal laser-scanning microscope (LSM 700; Carl Zeiss SAS, Le Pecq, France). Morphometric analyses were made using ImageJ software version $1.49 \mathrm{~m}(\mathrm{NIH}$, Bethesda, MD) and a homemade macro. The smallest diameter (minimum Ferret) of all of the muscle fibers of the whole muscle section was measured. Herein, only data from pure myosin heavy chain $-2 b$, myosin heavy chain $-2 x$, and myosin heavy chain-2a fiber types were analyzed. Myosin heavy chain $-2 x$ fibers were identified as fibers that did not express myosin heavy chain-2b, myosin heavy chain-2a, and myosin heavy chain-1. For muscle fiber diameter and fiber typing analyses, all of the muscle fibers of the muscle section were measured. The extent of fibrosis was assessed by Sirius red staining.

\section{Gel Electrophoresis for the Determination of Myosin Heavy Chain}

Plantaris muscles were extracted on ice for 60 minutes in four volumes of extracting buffer ( $\mathrm{pH}$ 6.5), as previously described. ${ }^{41}$ After centrifugation, the supernatants were diluted 1:1 (v/v) with glycerol and stored at $-20^{\circ} \mathrm{C}$. Myosin heavy chain isoforms were separated onto $8 \%$ polyacrylamide gels, which were made in the Bio-Rad (Marnes-la-Coquette, France) mini-Protean II Dual slab cell system, as described previously. ${ }^{42-44}$ The gels were migrated for 31 hours at $72 \mathrm{~V}$ (constant voltage) at $4^{\circ} \mathrm{C}$. For the quantification of the relative concentration of myosin heavy chain and actin, $1 \mu \mathrm{g}$ of total proteins was loaded and $12 \%$ polyacrylamide gels were used. ${ }^{45}$ The silver-stained gels were scanned using a video acquisition system, and bands were quantified by densitometric software version 381472 (Multi Gauge; Fujifilm, Asnières, France). 
A

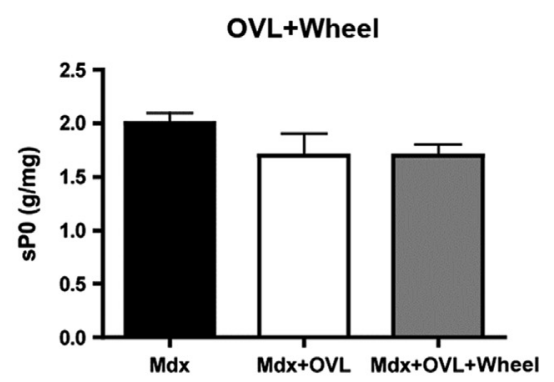

D

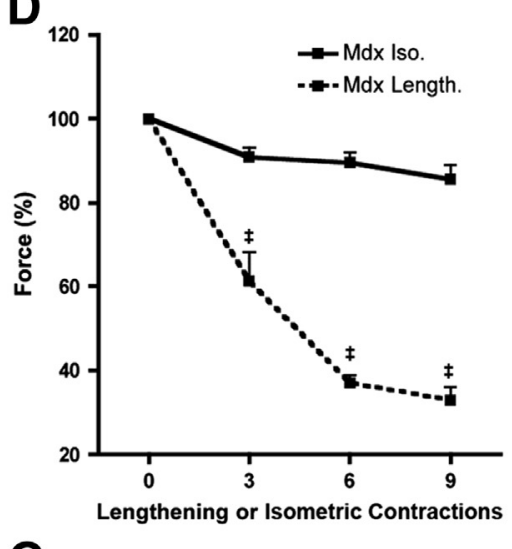

G

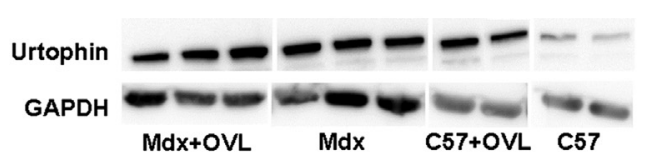

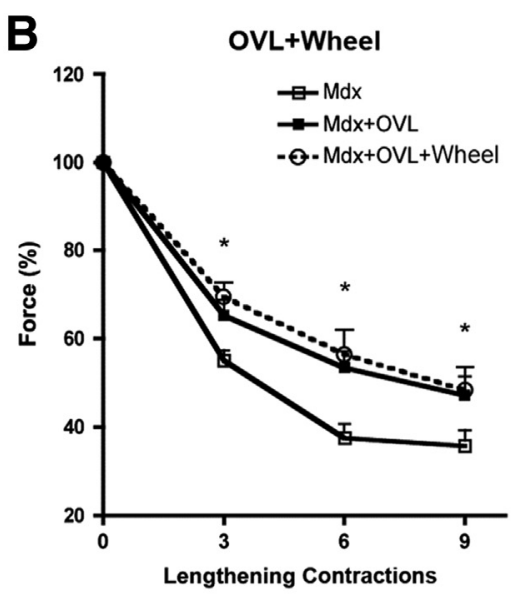
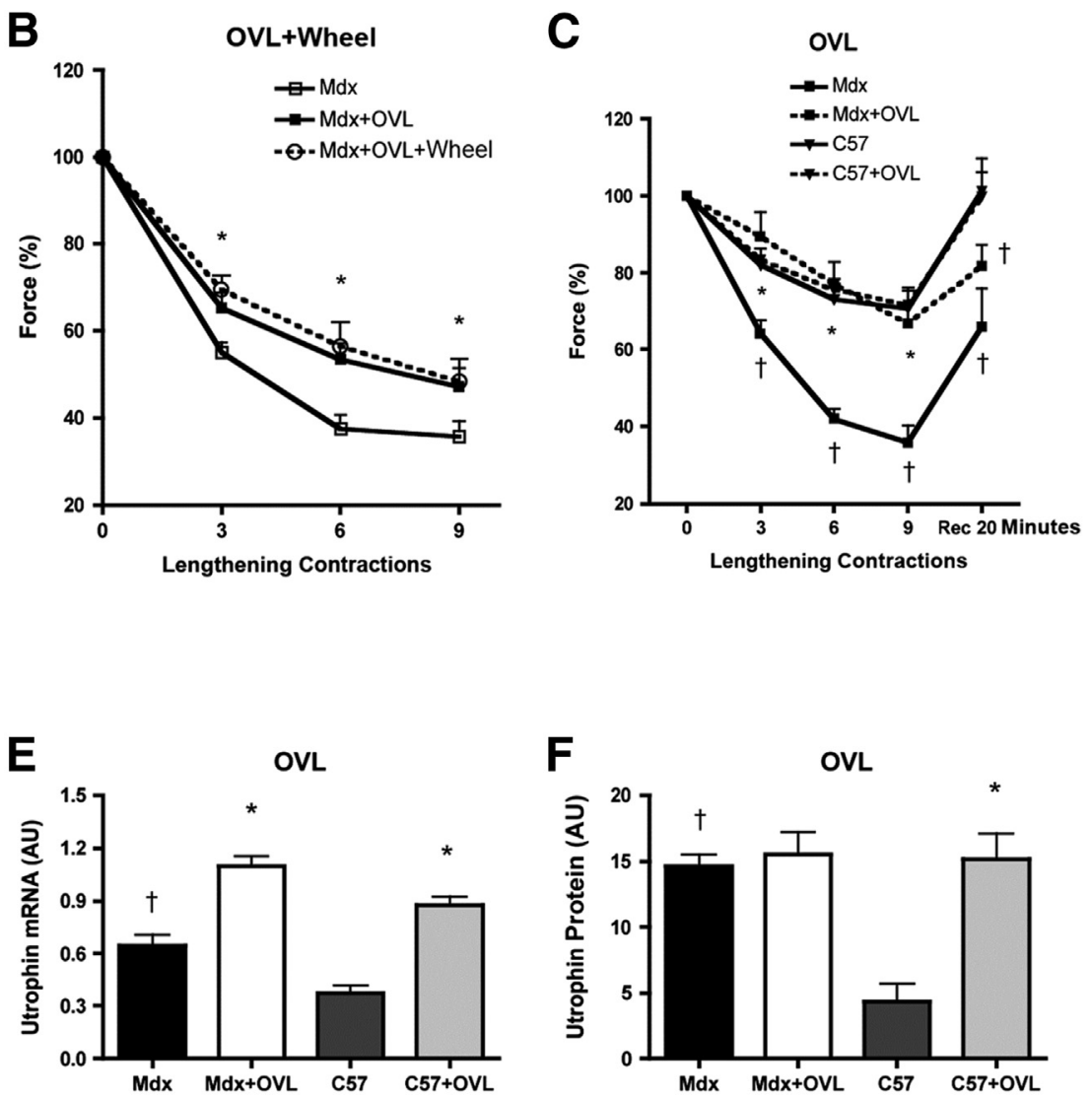

Figure 1 Functional dystrophic features in response to short-term overloading (OVL) and short-term OVL combined with wheel running in $\mathrm{mdx}$ mice. A: Specific maximal force in $\mathrm{mdx}$ mice (sP0). B-F: Force decrease after lengthening contractions in $\mathrm{mdx}$ mice (B), lengthening contractions in $\mathrm{mdx}$ and $\mathrm{C} 57$ mice (C), and isometric (Iso.) or lengthening (Length.) contractions in $\mathrm{mdx}$ mice (D). Utrophin mRNA (E) and protein (F) levels in $\mathrm{mdx}$ and $\mathrm{C} 57$ mice. G: Representative images of blots concerning utrophin. $n=9$ to 14 per group (A and $\mathbf{B}$ ); $n=4$ to 12 per group (C and $\mathbf{D}$ ); $n=3$ to 5 per group (E and $\mathbf{F})$. ${ }^{*} P<0.05,0 \mathrm{VL}$ mice; ${ }^{\dagger} P<0.05, \mathrm{C} 57$ mice; ${ }^{\ddagger} P<0.05$, isometric contractions. AU, arbitrary unit; GAPDH, glyceraldehyde-3-phosphate dehydrogenase.

\section{Immunoblotting}

Plantaris was powdered on dry ice and homogenized in $300 \mu \mathrm{L}$ of ice-cold lysis buffer $[50 \mathrm{mmol} / \mathrm{L}$ Tris $\cdot \mathrm{HCl}(\mathrm{pH} 7.5), 250$ $\mathrm{mmol} / \mathrm{L}$ sucrose, $1 \mathrm{mmol} / \mathrm{L}$ EDTA, $1 \mathrm{mmol} / \mathrm{L}$ EGTA, $0.25 \%$ Nonidet P-40 substitute, $50 \mathrm{mmol} / \mathrm{L} \mathrm{NaF}, 5 \mathrm{mmol} / \mathrm{L} \mathrm{Na}_{4} \mathrm{P}_{2} \mathrm{O}_{7}$, $0.1 \%$ dithiothreitol, fresh antiprotease, and phosphatase inhibitor mixture]. Then, samples were shaken at $1300 \mathrm{rpm}$ for 30 minutes at $4{ }^{\circ} \mathrm{C}$. Samples were subsequently centrifuged at $13,000 \times g$ for 10 minutes at $4^{\circ} \mathrm{C}$, and the protein concentration of the supernatant was determined by the Bradford assay (Bio-Rad). Equal aliquots of protein were boiled for 5 minutes in Laemmli sample buffer $[250 \mathrm{mmol} / \mathrm{L}$ Tris $\cdot \mathrm{HCl}(\mathrm{pH} 6.8), 2 \%(\mathrm{v} / \mathrm{v}) \mathrm{SDS}, 10 \%$ $(\mathrm{v} / \mathrm{v})$ glycerol, $0.01 \%$ bromophenol blue, and $5 \%(\mathrm{v} / \mathrm{v})$ $\beta$-mercaptoethanol]. Samples were separated onto SDSpolyacrylamide gels and then transferred to nitrocellulose membranes for 1 hour. Membranes were blocked for 1 hour in $3 \%$ milk in Tris-buffered saline and $0.1 \%$ Tween 20 (TBST) before overnight incubation at $4{ }^{\circ} \mathrm{C}$ with appropriate primary antibody in TBST (1:1000 dilution). Proteins were detected with a primary antibody directed to utrophin A (NCL-DRP2; Leica, Newcastle, UK), peroxisome proliferator-activated receptor $\gamma$ coactivator 1- $\alpha$ (sc13067; Santa Cruz Biotechnology), phospho-AMP activated protein kinase $\alpha$ (mAb2535; Cell Signaling Technology, Leiden, the Netherlands), complex IV subunit IV (A21348; Life Technologies), and glyceraldehyde-3-phosphate dehydrogenase (sc365062; Santa Cruz Biotechnology). After incubation, membranes were washed three times with TBST before incubation with an appropriate peroxidase-conjugated secondary antibody (Santa Cruz Biotechnology) in TBST. Antibody binding was detected using an enhanced chemiluminescence horseradish peroxidase substrate detection kit (Thermo Fisher Scientific, Saint Herblain, France) and quantified using ImageJ software.

\section{Quantitative RT-PCR}

Total RNA was extracted from TA muscle using TRIzol (Life Technologies) and Ultra Turrax (Ika, Staufen, Germany), 

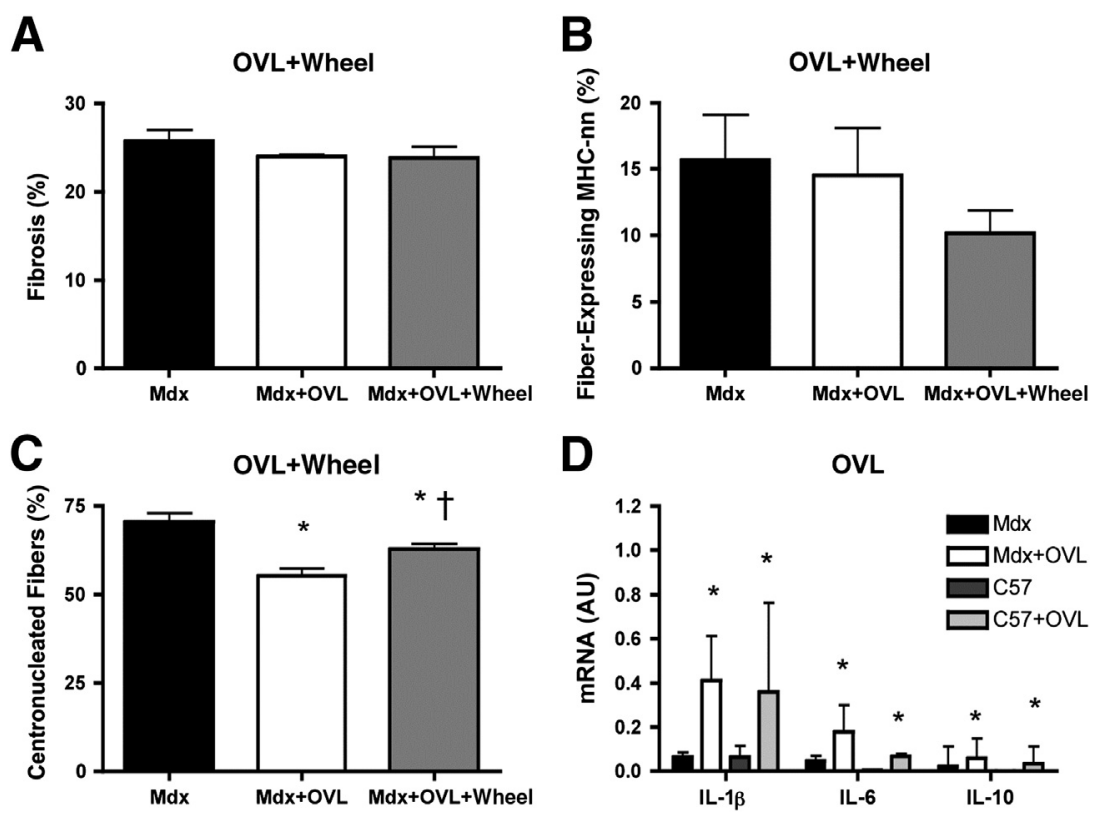

Figure 2 Cellular and molecular dystrophic features in response to short-term overloading (OVL) and short-term OVL combined with wheel running in $\mathrm{mdx}$ mice. A: Fibrosis in mdx mice. B: Fibers expressing the neonatal isoform of myosin heavy chain (MHC-nn) in $\mathrm{mdx}$ mice. C: Centronucleated fibers in $\mathrm{mdx}$ mice. D: mRNA levels of different inflammatory cytokines in $\mathrm{mdx}$ and $\mathrm{C} 57$ mice. $n=3$ to 5 per group for cellular and molecular measurements. ${ }^{*} P<0.05$, nonoverloaded mice; ${ }^{\dagger} P<0.05$, overloaded mice. $\mathrm{AU}$, arbitrary unit. following the manufacturer's instructions. From $500 \mathrm{ng}$ of extracted RNA, the first-strand cDNA was then synthesized using the RevertAid Reverse Transcriptase (Thermo Fisher Scientific, Villebon-sur-Yvette, France) with Oligo $(\mathrm{dT})_{18}$ primer and according to the manufacturer's instructions. Primer sequences were designed with Primer-BLAST (http://www. ncbi.nlm.nih.gov/tools/primer-blast), ${ }^{46}$ as follows: $\beta$-2-microglobulin forward, 5'-CACACTGAATTCACCCCCAC-3', reverse, 5'-GTCTCGATCCCAGTAGACGG-3'; cytochrome c oxidase subunit IV isoform 1 forward, 5'-CGTCTTGGTCTTCCGGTTG-3', reverse, 5'-TCTGGAAGCCAACATTCTGC-3'; citrate synthase forward, 5'-CATGCCAGTGCTTCTTCCA-3' ${ }^{\prime}$, reverse, 5'-CATGTTGCTGCTTGAAGGTCT-3'; cytochrome c-1 forward, 5'-TTTTCCCTGCTCACTGGCTA- $3^{\prime}$, reverse, $5^{\prime}$-TGGGGTGCCATCATCATACT3'; desmin forward, 5'-GTCCTCACTGCCTCCTGAAG-3', reverse, 5'-AGCATGAAGACCACAAAGGG-3'; hydroxymethylbilane synthase forward, 5'-AGGTCCCTGTTCAGCAAGAA-3', reverse, 5'-TGGGCTCCTCTTGGAATGTT-3'; interferon $\gamma$ forward, 5'-GTTTGAGGTCAACAACCCACA-3' ${ }^{\prime}$, reverse, 5'-ACTCCTTTTCCGCTTCCTGA-3'; IL-10 forward, 5'-GGCGCTGTCATCGATTTCTC-3' ${ }^{\prime}$, reverse, $5^{\prime}$-GCCTTGTAGACACCTTGGTC- $3^{\prime}$; Il13 forward, 5'-CATCACACAAGACCAGACTCC-3', reverse, 5'-GGTTACAGAGGCCATGCAAT-3'; IL-1 $\beta$ forward, 5'-AAGGAGAACCAAGCAACGAC-3', reverse, 5' CTTGGGATCCACACTCTCCAG-3'; IL-4 forward, 5'TCTGTAGGGCTTCCAAGGTG-3', reverse, 5'-TCTGCAGCTCCATGAGAACA-3'; IL-6 forward, 5'-TCTCTGCAAGAGACTTCCATCC-3', reverse, 5'-AAGTCTCCTCTCCGGACTTG-3'; myosin, heavy polypeptide 7, cardiac muscle, $\beta$ forward, 5'-AGGTGTGCTCTCCAGAATGG-3', reverse, 5'-CAGCGGCTTGATCTTGAAGT3'; Nrf1 forward, 5'-TGGAGTCCAAGATGCTAATGG-3', reverse, 5'-GCGAGGCTGGTTACCACA-3'; peroxisome proliferator-activated receptor (Ppar)a forward, 5'-CCGAGGGCTCTGTCATCA-3', reverse, 5'-GGGCAGCTGACTGAGGAA-3'; Ppard forward, 5'-ATGGGGGACCAGAACACAC-3', reverse, 5'-GGAGGAATTCTGGGAGAGGT-3'; Pparg forward, 5'-ACTCGCATTCCTTTGACATC- $3^{\prime}$, reverse, 5'-TCGCACTTTGGTATTCTTGG-3'; Ppargc 1 a forward, 5'-GAAAGGGCCAAACAGAGAGA-3', reverse, 5'-GTAAATCACACGGCGCTCTT-3'; Pprc1 forward, 5'-CTGTCGAGTCTGTTGGAGCA-3', reverse, 5'-ACAGCCAAGCTGTCAGCAG-3'; succinate deshydrogenase $(\mathrm{Sdh})$ a forward, 5'-TTACAAAGTGCGGGTCGATG-3', reverse, 5'-GTGTGCTTCCTCCAGTGTTC-3'; Sirtuin (Sirt)1 forward, 5'-TCGTGGAGACATTTTTAATCAGG-3', reverse, 5'-GCTTCATGATGGCAAGTGG-3'; Sirt 2 forward, 5'-CACTACTTCATCCGCCTGCT-3', reverse, 5'-CCAGCGTGTCTATGTTCTGC-3'; Sirt3 forward, 5' TGCTACTCATTCTTGGGACCTC-3', reverse, 5'-GGGCACTGATTTCTGTACTGC-3'; transcription factor A forward, 5'-GCAGGCACTACAGCGATACA-3', reverse, 5'-ACTGAGCTCCGAGTCCTTGA-3'. Relative quantification PCR analysis was then performed with green intercalating dye PCR technology using a LightCycler 480 Real-Time PCR System (Roche Diagnostics, Meylan, France). The reaction was performed in duplicate for each sample in a $6-\mu \mathrm{L}$ reaction volume made up of $3 \mu \mathrm{L}$ of The LightCycler 480 SYBR Green I Master (Roche Diagnostics) containing $1 \mu \mathrm{mol} / \mathrm{L}$ each of the forward and reverse primer and $3 \mu \mathrm{L}$ of diluted $(1: 25) \mathrm{cDNA}$. The thermal profile for quantitative PCR was $95^{\circ} \mathrm{C}$ for $1 \mathrm{~min}$ ute, followed by 40 cycles at $95^{\circ} \mathrm{C}$ for 15 seconds, $60^{\circ} \mathrm{C}$ for 15 seconds, and $72^{\circ} \mathrm{C}$ for 30 seconds. The gene expression of hydroxymethylbilane synthase was used as the reference transcript. 

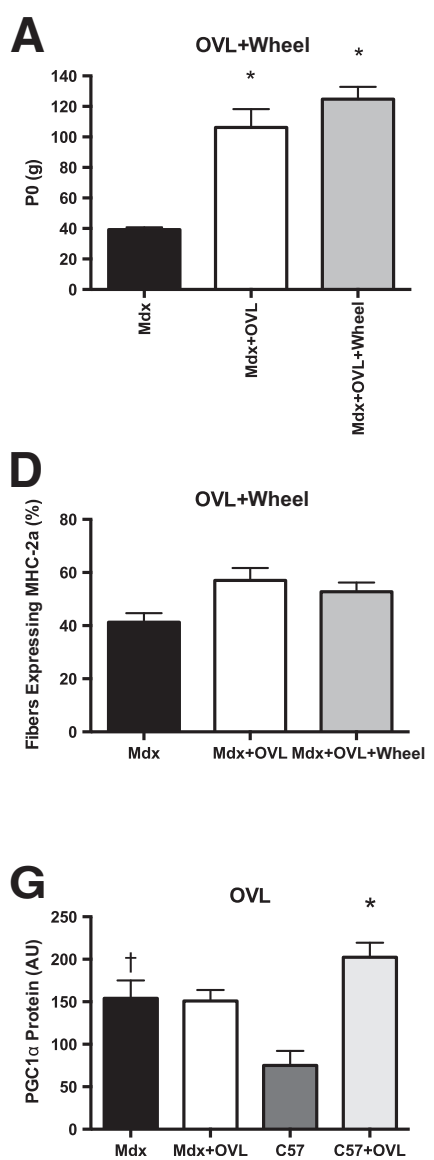

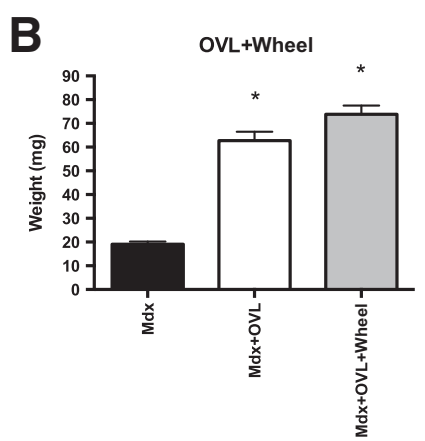

$\mathbf{E}$

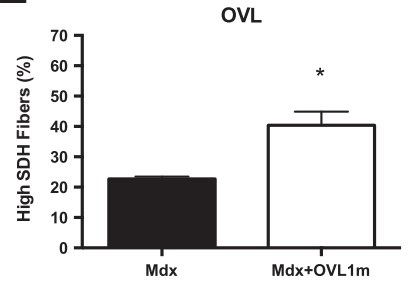

$\mathbf{H}$

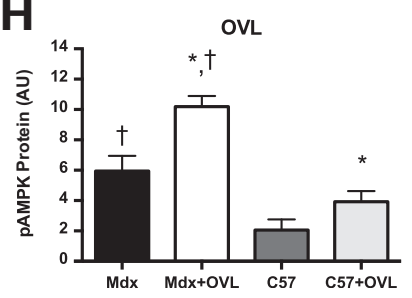

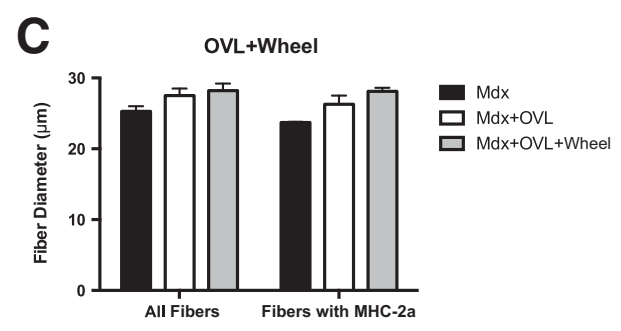

$\mathbf{F}$
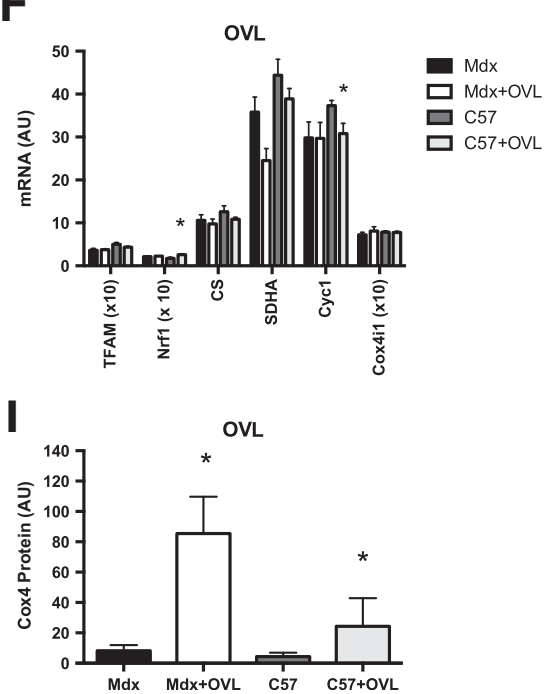

Figure 3 Functional, cellular, and molecular muscle adaptations in response to short-term overloading (OVL) and short-term OVL combined with wheel running in mdx mice. A: Absolute maximal force (PO). B: Muscle weight. C: Fiber diameter. D: Percentage of fibers expressing myosin heavy chain (MHC)-2a. The percentage increased but not significantly $(P=0.09)$. E: Percentage of highly succinate deshydrogenase (SDH)-stained fibers. F: mRNA levels of genes regulating mitochondria biogenesis (TFAM and NrF1) and involved in citric cycle and respiratory chain (CS, SDHA, Cyc1, and Cox4i1). G: Protein level of PGC-1 $\alpha$. H: Protein level of phosphorylated AMP activated protein kinase $\alpha$. I: Protein level of Cox4. $n=9$ to 14 per group for functional measurements; $n=3$ to 5 per group for cellular and molecular measurements. ${ }^{*} P<0.05$, nonoverloaded mice; ${ }^{\dagger} P<0.05$, C57 mice. AU, arbitrary unit; $\mathrm{PGC}-1 \alpha$, peroxisome proliferatoractivated receptor $\gamma$ coactivator $1-\alpha$.

\section{Statistical Analysis}

Groups were statistically compared using analysis of variance (one and two ways) and Student's $t$-test, as appropriate. If necessary, subsequent post hoc analysis (Bonferroni) was also performed. Values are given as means \pm SEM.

\section{Results}

\section{Effect of Short-Term OVL Combined with Wheel Running}

Ablation of synergic plantaris muscles (mechanical OVL and OVL) was performed at the age of 2 to 3 months, and the mice were studied 1 month later. During the OVL period, some of the mdx mice were placed in cages containing a wheel, in which they ran $3.5 \pm 0.5 \mathrm{~km} /$ day. We first determined whether the functional dystrophic features worsened when OVL was combined with wheel running. By using muscle contractility analysis, we observed that specific maximal force was unchanged in response to OVL in both $\mathrm{mdx}+\mathrm{OVL}+$ wheel and
$\mathrm{mdx}+\mathrm{OVL}$ mice (Figure 1A). Moreover, the force decreases after the sixth and ninth lengthening contractions were reduced in response to OVL in both $\mathrm{mdx}+\mathrm{OVL}+$ wheel and mdx +OVL mice (Figure 1B), indicating that susceptibility to contraction-induced muscle damage was improved in both $\mathrm{mdx}+\mathrm{OVL}+$ wheel and $\mathrm{mdx}+\mathrm{OVL}$ mice. The improvement in force decrease was similar in $\mathrm{mdx}+\mathrm{OVL}+$ wheel and $\mathrm{mdx}+\mathrm{OVL}$ mice because we observed no difference between $\mathrm{mdx}+\mathrm{OVL}+$ wheel and $\mathrm{mdx}+\mathrm{OVL}$ mice. Next, we performed additional experiments to better characterize the reduced force decreases after lengthening contractions. To test whether this improvement induced by OVL was specific to dystrophic muscles, we also analyzed the effect of 1-month OVL in C57 mice expressing dystrophin. We observed that the force decreases after the lengthening contractions in C57+OVL mice were not different from those of C57 mice (Figure 1C). Moreover, we confirmed that OVL improved the force decreases after the third, sixth, and ninth lengthening contractions in $\mathrm{mdx}+\mathrm{OVL}$ mice because these were reduced compared with those of mdx mice (Figure 1C) and not different from those of C57+OVL mice (Figure 1C). We also 

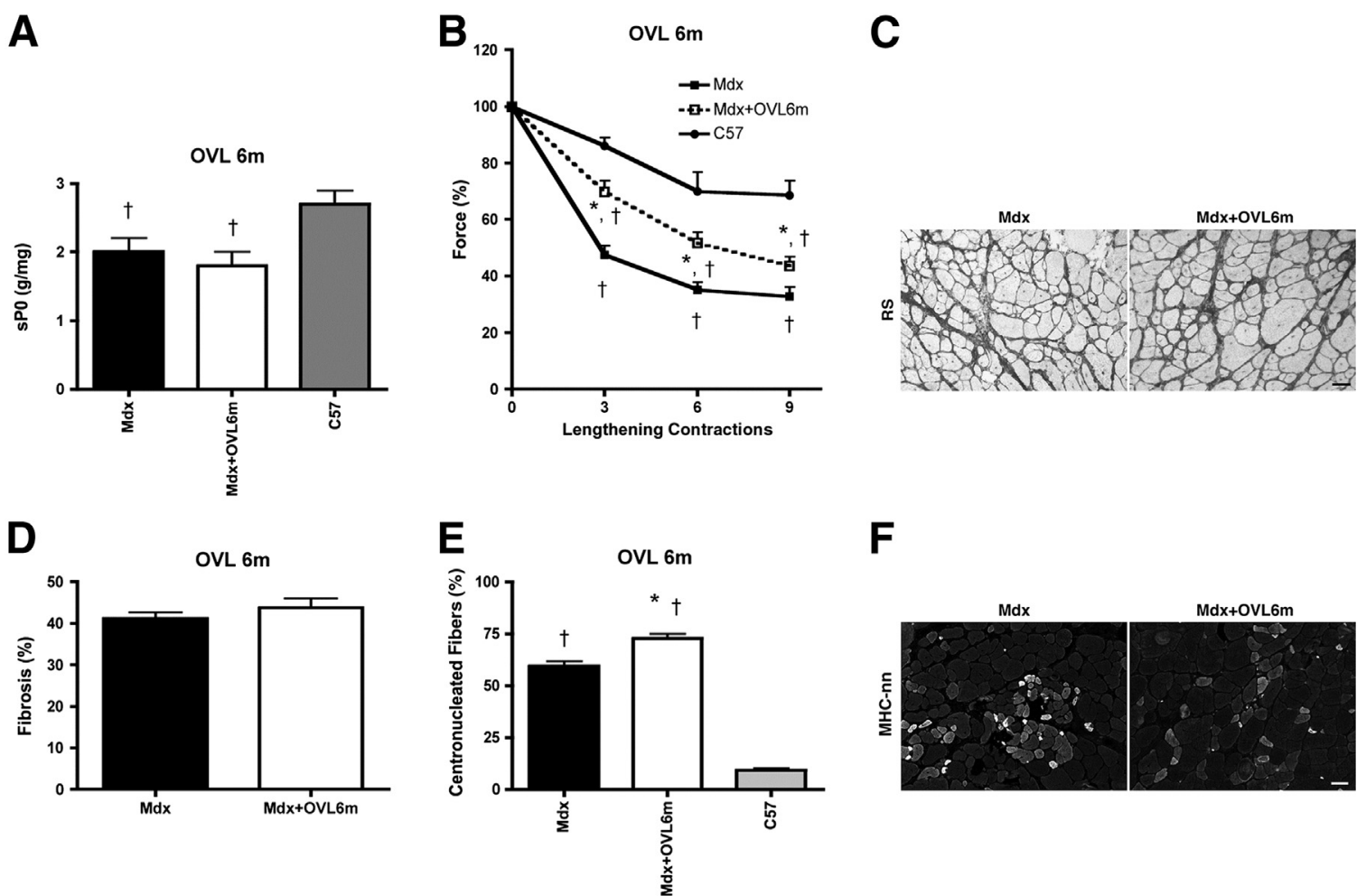

$\mathbf{F}$

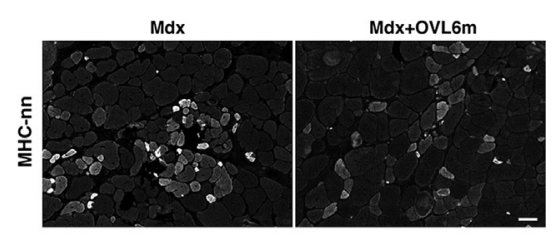

Figure 4 Functional, cellular, and molecular dystrophic features in response to long-term overloading (OVL) in mdx mice. A: Specific maximal force (sP0). B: Force decrease after lengthening contractions. C: Representative image of fibrosis, using Sirius red staining. D: Fibrosis. E: Centronucleated fibers. F: Representative image of the neonatal isoform of myosin heavy chain (MHC-nn)-expressing fibers. $n=12$ to 14 per group for functional measurements; $n=6$ per group for cellular and molecular measurements. ${ }^{*} P<0.05$, nonoverloaded mice; ${ }^{\dagger} P<0.05$, C57 mice. Scale bar $=30 \mu \mathrm{m}(\mathbf{C}$ and $\mathbf{F})$. RS, sarcoplasmic reticulum.

observed that the force decrease 20 minutes after the ninth lengthening contraction was reduced, but not significantly, in $\mathrm{mdx}+\mathrm{OVL}$ compared with $\mathrm{mdx}$ (Figure 1C). The major portion of the force decrease after lengthening contractions in $\mathrm{mdx}$ mice was not because of fatigue (metabolic incompetency) because nine isometric contractions did not result in a similar force decrease after contractions (Figure 1D). Because utrophin is a dystrophin homologue that is up-regulated in mdx mice to compensate dystrophin deficiency, we then determined whether the improvement in the force decrease after lengthening contractions in $\mathrm{mdx}+\mathrm{OVL}$ was related to increased utrophin expression. Quantitative PCR analysis revealed that utrophin mRNA levels were increased by OVL in both mdx and C57 mice (Figure 1E). However, the utrophin protein level was unchanged in $\mathrm{mdx}+\mathrm{OVL}$ compared with mdx (Figure 1, F and G).

Cellular and molecular aspects of dystrophic features were evaluated by observing histological markers of muscle damage/ regeneration. Results showed that fibrosis (Figure 2A) and the percentage of muscle fibers expressing myosin heavy chain-neonatal (Figure 2B) did not increase in response to OVL in both $\mathrm{mdx}+\mathrm{OVL}+$ wheel and $\mathrm{mdx}+\mathrm{OVL}$ mice and were not different between these two groups of mice. Moreover, the percentage of centronucleated muscle fibers was reduced in response to OVL in both $\mathrm{mdx}+\mathrm{OVL}+$ wheel and $\mathrm{mdx}+\mathrm{OVL}$ mice (Figure 2C); however, this occurred to a lesser extent in $\mathrm{mdx}+\mathrm{OVL}+$ wheel compared with $\mathrm{mdx}+\mathrm{OVL}$ mice.
Additional experiments indicated that the expression of IL-1 $\beta$, IL-6, and IL-10, markers of inflammation, was similarly increased in both mdx and C57, as assessed by quantitative PCR analysis (Figure 2D).

Concerning the functional, cellular, and molecular adaptations induced by OVL, we observed that absolute maximal force similarly increased in $\mathrm{mdx}+\mathrm{OVL}+$ wheel $(218 \%)$ and $\mathrm{mdx}+\mathrm{OVL}(171 \%)$ mice (Figure 3A). We also observed that muscle weight similarly increased in response to OVL in $\mathrm{mdx}+\mathrm{OVL}+$ wheel $(286 \%)$ and $\mathrm{mdx}+\mathrm{OVL}(228 \%)$ mice (Figure 3B). Next, muscle hypertrophy was characterized by immunohistology. The fiber diameter did not change in response to OVL in both $\mathrm{mdx}+\mathrm{OVL}+$ wheel and $\mathrm{mdx}+\mathrm{OVL}$ mice (Figure 3C), indicating that the increased muscle weight induced by OVL was caused by an increased number of fibers per cross section. Regarding the potential fiber-type transition induced by OVL, we observed that both $\mathrm{mdx}+\mathrm{OVL}+$ wheel and $\mathrm{mdx}+\mathrm{OVL}$ mice increased the percentage of fibers expressing myosin heavy chain-2a, although this was not significant (Figure 3D). Muscle sections were also treated to show SDH activity, an enzyme of the citric acid cycle/complex II of the respiratory chain. We showed that the percentage of high stained SDH fibers was greater in $\mathrm{mdx}+\mathrm{OVL}$ mice compared with mdx mice (Figure 3E). Additional experiments were also performed to further analyze the fiber transition induced by OVL. Although gene expression was not markedly increased (Figure 3F), immunoblotting analysis revealed that 
A

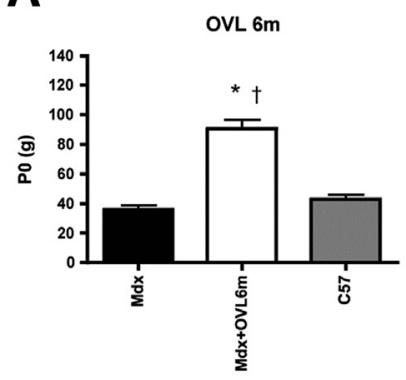

D

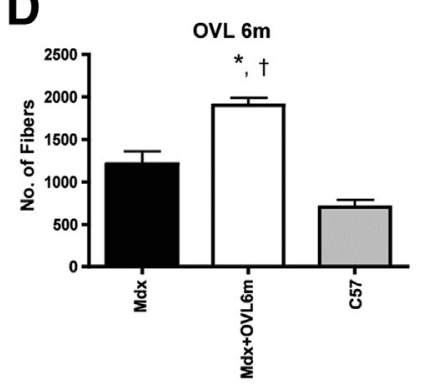

G

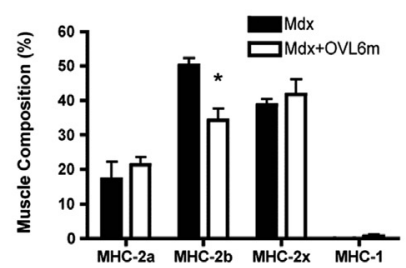

B

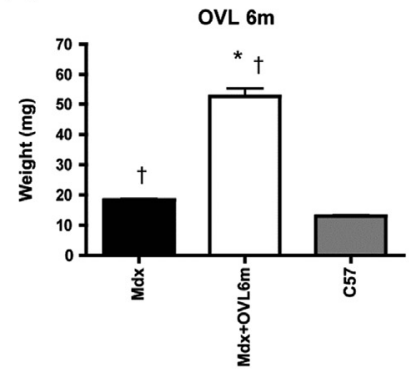

E
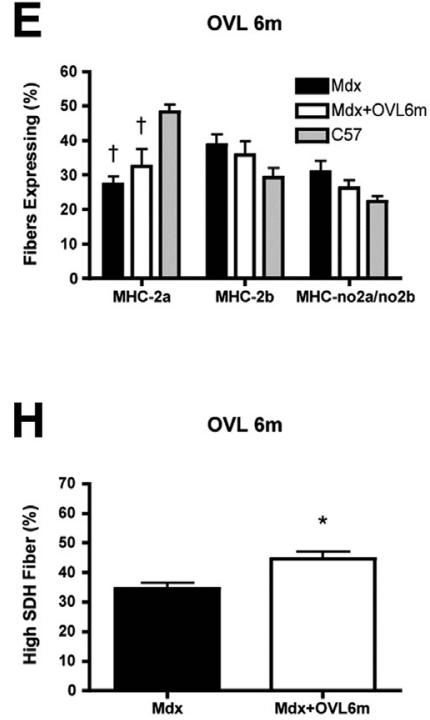

C OVL $6 \mathrm{~m}$

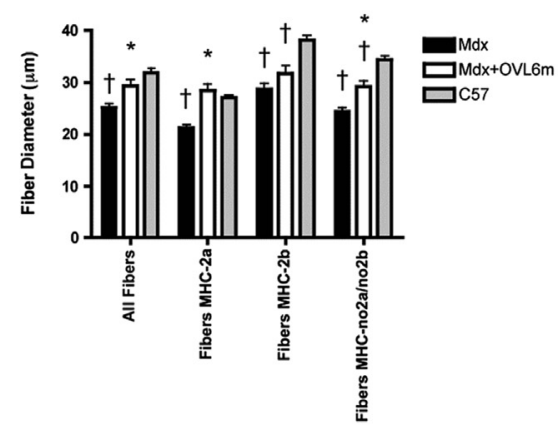

$\mathbf{F}$

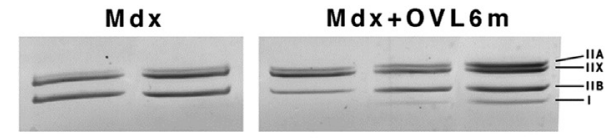

Figure 5 Functional, cellular, and molecular muscle adaptations in response to long-term overloading (OVL) in mdx mice. Absolute maximal force (PO; A), muscle weight (B), fiber diameter (C), total fiber number per cross section (D), percentage of fibers expressing the neonatal isoform of myosin heavy chain (MHC)-2a, MHC-2b, or no MHC (E), representative image of electrophoretic separation of MHC isoforms (F), MHC-2a, MHC-2b, MHC-2x, and MHC-1 composition $(\mathbf{G})$, and the percentage of highly succinate deshydrogenase (SDH)-stained fibers $(\mathbf{H}) . n=12$ to 14 per group for functional measurements; $n=6$ per group for cellular and molecular measurements. ${ }^{*} P<0.05$, nonoverloaded mice; ${ }^{\dagger} P<0.05$, C57 mice.

several markers of oxidative energy metabolism increase in $\mathrm{mdx}+\mathrm{OVL}$ (or C57+OVL) mice (Figure 3, G-I).

In conclusion, we observed no notable difference between $\mathrm{mdx}+\mathrm{OVL}+$ wheel and $\mathrm{mdx}+\mathrm{OVL}$ mice. Therefore, our results indicate that there was no notable effect of wheel running in mdx mice during OVL: dystrophic features were not worsened, and functional, cellular, and molecular adaptations in response to OVL were not impaired.

\section{Effect of Long-Term OVL}

Synergic plantaris muscle ablation was performed at 2 to 3 months of age, and the mice were studied 6 months later. We observed no effect of 6-month OVL on specific maximal force because there was no difference between $\mathrm{mdx}+\mathrm{OVL} 6 \mathrm{~m}$ and mdx mice (Figure 4A). However, the force decrease after lengthening contractions was reduced in response to 6-month OVL (Figure 4B), indicating an improvement of this functional dystrophic feature. Fibrosis was not increased in response to 6-month OVL (Figure 4, C and D). The percentage of centronucleated fibers was slightly increased by 6-month OVL
(Figure 4E), whereas the percentage of fibers expressing myosin heavy chain-nn was not different between mdx+OVL6m $(16.0 \% \pm 2.4 \%)$ and $m d x$ mice $(16.1 \% \pm 2.5 \%)$. As shown in Figure $4 \mathrm{~F}$, the level of staining was reduced in mdx +OVL6m compared with mdx mice. Together, these results indicate that histological markers of muscle damage (ie, cellular and molecular dystrophic features) were not worsened by 6-month OVL.

Functional, cellular, and molecular adaptations in response to 6-month OVL showed that absolute maximal force increased by $151 \%$ in $\mathrm{mdx}+$ OVL6m compared with mdx (Figure $5 \mathrm{~A}$ ). Moreover, muscle was heavier (188\%) in mdx+OVL6m (Figure 5B). This hypertrophy was because of both increased fiber diameter (13\%) (Figure 5C) and total fiber number per cross section (74\%) in mdx+OVL6m (Figure 5D). We observed no change in the percentage of the different fiber types in response to 6-month OVL (Figure 5E). However, analysis of the myosin heavy chain composition, as assessed by gel electrophoresis, showed that myosin heavy chain $-2 \mathrm{~b}$ expression was decreased in mdx +OVL6m compared with mdx (Figure 5, $\mathrm{F}$ and $\mathrm{G})$. Moreover, the percentage of high stained SDH fibers increased in response to 6-month OVL (Figure 5H). 

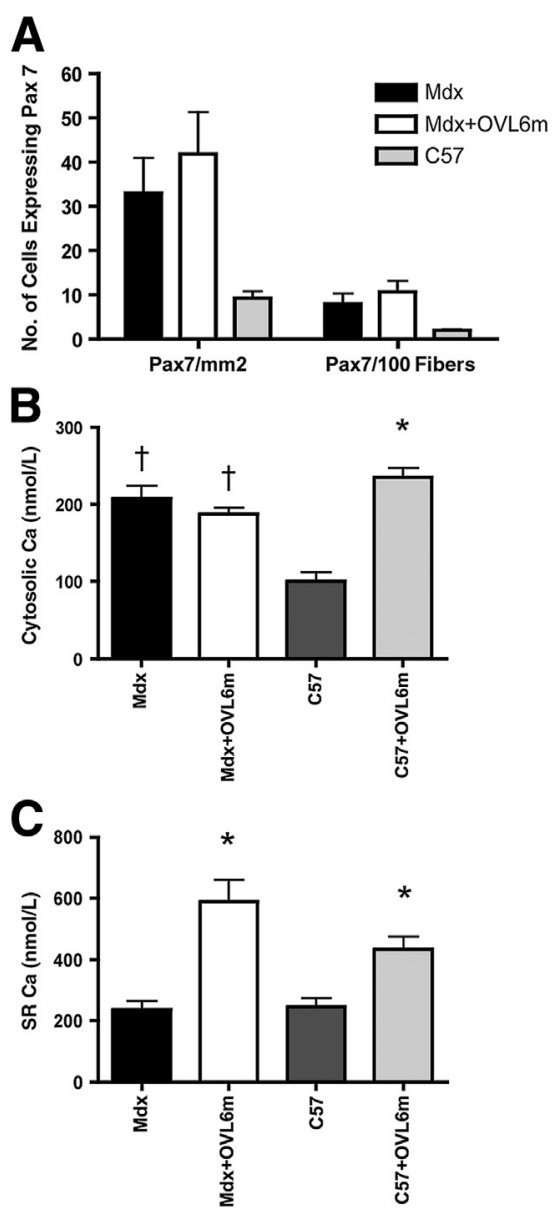

Figure 6 Muscle cell progenitors (satellite cells) and calcium homeostasis in response to long-term overloading $(\mathrm{OVL})$ in $\mathrm{mdx}$. Number of cells expressing Pax 7 in plantaris muscle (A), resting cytosolic calcium content in extensor digitorum longus (EDL) fiber bundles (B), and resting sarcoplasmic reticulum (SR) calcium content in EDL fiber bundles (C). ${ }^{*} P<0.05$, nonoverloaded mice; ${ }^{\dagger} P<0.05$, C57. $n=6$ per group for cellular measurements; $n=29$ to 101 per group for calcium measurements.

To determine whether 6-month OVL depleted muscle cell progenitors, we counted the number of satellite cells in a muscle section. We observed that 6-month OVL did not change the number of satellite cells expressing Pax 7 (Figure 6A).

In addition, we also studied calcium homeostasis, by using fura-2 microfluorescence analysis, in EDL muscle after longterm OVL ( 5 to 6 months). Fiber bundles of EDL muscles were used for this analysis because it was not possible to prepare fiber bundles from the plantaris muscles. We observed that calcium homeostasis did not worsen by 6-month OVL because resting cytosolic calcium content did not increase in $\mathrm{mdx}+$ OVL6m compared with mdx (Figure 6B). Six-month OVL induced an increase in resting sarcoplasmic reticulum calcium content in $\mathrm{mdx}+$ OVL6m and C57+OVL6m mice, indicating that this calcium adaptation in response to OVL was maintained in $\mathrm{mdx}+$ OVL6m (Figure 6C).

Together, these results indicate that long-term OVL did not worsen dystrophic features and did not deplete muscle cell progenitors. Moreover, mdx mice exhibited typical functional, cellular, and molecular adaptations in response to long-term OVL.

\section{Effect of Short-Term OVL Combined with Prior Irradiation}

Because muscle regeneration could mask the potential deleterious effect of OVL, the left hind limb was irradiated before ablation of synergic plantaris muscles, to inhibit satellite cell proliferation and thus muscle repair. Plantaris muscles were studied after 1-month OVL. Irradiation similarly decreased specific maximal force in $\mathrm{mdx}+\mathrm{OVL}+$ irr and $\mathrm{C} 57+\mathrm{OVL}+\mathrm{irr}$ mice compared with $\mathrm{mdx}+\mathrm{OVL}(-58 \%)$ and $\mathrm{C} 57+\mathrm{OVL}$ $(-64 \%)$, respectively (Figure 7, A and B). In contrast to C57+OVL+irr mice, specific maximal force was not decreased in $\mathrm{mdx}+\mathrm{OVL}+$ irr mice compared with mdx, indicating that this dystrophic feature was not worsened by OVL combined with irradiation. Absolute maximal force (Figure 7, C and D) and muscle weight (Figure 7, E and F) were similarly reduced in $\mathrm{mdx}+\mathrm{OVL}+\mathrm{irr}(-87 \%$ and $-69 \%)$ and C57+OVL+irr $(-90 \%$ and $-72 \%)$ mice compared with $\mathrm{mdx}+\mathrm{OVL}$ and C57+OVL mice, respectively. Together, these results indicate that OVL did not induce more detrimental effects in $\mathrm{mdx}$ than in C57 mice, when plantaris muscles were irradiated before synergic muscle ablation.

\section{Discussion}

\section{Dystrophic Features Do Not Worsen but Improve}

In the present study, short-term OVL combined with wheel running and long-term OVL have been shown to be not detrimental to mdx mice because they did not worsen the deficit in maximal specific force, histological markers of muscle damage, or calcium homeostasis, confirming and extending our previous study. ${ }^{17}$ These results are also supported by the fact that irradiation before short-term OVL did not induce more deleterious effects in mdx than in C57 mice. It is believed that satellite cells are essential for muscle remodeling in response to OVL. ${ }^{47,48}$ Because irradiation blocked similarly the gains in absolute maximal force and muscle weight in response to short-term OVL in mdx and C57 mice, this confirms that satellite cell function was efficiently inhibited in both mice strains, and thus irradiated muscles from overloaded mdx mice were unable to regenerate. Therefore, these latter findings suggest that muscle regeneration did not mask the deleterious effects of OVL in unirradiated mdx muscle.

Interestingly, we demonstrate, for the first time, that both short-term OVL+ wheel and long-term OVL improved one of the major dystrophic features: susceptibility to contractioninduced damage. This effect of OVL is specific to mdx muscle because the force decrease after lengthening contractions remains unchanged in C57 mice, suggesting that the mechanism of the force decrease after lengthening contractions differs between mdx and C57 mice. It remains to be determined whether 

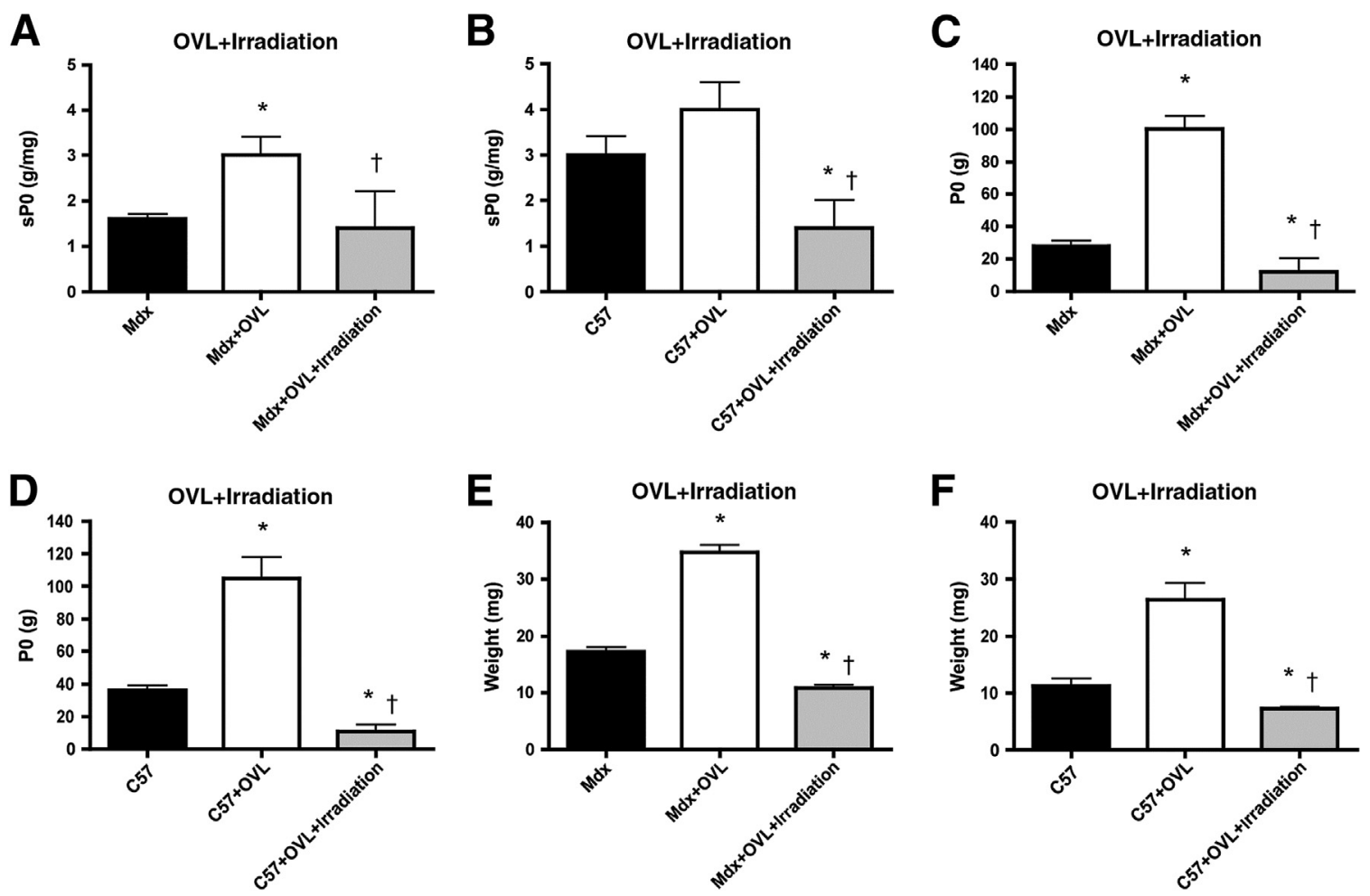

Figure 7 Functional dystrophic features and muscle adaptations in response to short-term overloading (OVL) combined with prior irradiation in mdx (A, C, and $\mathbf{E}$ ) and C57 (B, D, and F) mice. Specific maximal force (sP0) in $\mathrm{mdx}(\mathbf{A})$ and C57 (B) mice, absolute maximal force in $\mathrm{mdx}(\mathrm{P0} ; \mathbf{C})$ and $\mathrm{C57}$ (D) mice, and muscle weights in $\mathrm{mdx}(\mathbf{E})$ and $\mathrm{C} 57(\mathbf{F})$ mice. $n=3$ to 4 per group for functional measurements; $n=3$ per group for cellular and molecular measurements. ${ }^{*} P<0.05$, nonoverloaded mice; ${ }^{\dagger} P<0.05$, overloaded mice.

the reduced immediate force decrease after lengthening contractions in response to OVL in $\mathrm{mdx}$ mice could be because of either the increased mechanical load placed on muscle or the increased tonic activation. Removal of synergic muscles imposes forced stimuli because the mice use the remaining plantaris muscle for both movement and maintenance of posture. Thus, because the two types of stimuli coexist after OVL, it is not clearly defined whether the higher intensity of contractions has more impact than the increased duration of the muscle activity.

Because the major portion of the immediate force decrease after lengthening contractions is not related to increased fatigability because of energy metabolism incompetence (the present study ${ }^{9,49,50}$ ), it is unlikely that a better fatigue resistance induced by OVL in mdx mice ${ }^{17}$ can explain the reduced force decrease in $\mathrm{mdx}+\mathrm{OVL}$ mice. In view of the crucial role of utrophin in the force decrease after lengthening contractions in mdx mice, ${ }^{51,52}$ it should be reasonable to hypothesize that the increased utrophin protein level induced by OVL could explain the reduced force decrease. This hypothesis was also supported by the findings that OVL increases the expression of utrophin mRNA in mdx mice (the present study). ${ }^{53}$ However, we observed that utrophin protein level was not increased in $\mathrm{mdx}+\mathrm{OVL}$ mice. We also examined the possibility that the reduced force decrease could be related to a fast or glycolytic to slow or oxidative fiber-type transition in $\mathrm{mdx}+\mathrm{OVL}$, with the beneficial effect of this fiber-type shift in dystrophic muscle receiving much attention recently. ${ }^{54}$ It is well established that soleus muscles from $\mathrm{mdx}$ mice containing fibers expressing myosin heavy chain $-2 \mathrm{a}$ and myosin heavy chain -1 are less susceptible to contractioninduced damage than EDL muscle containing most fibers expressing myosin heavy chain-2b. ${ }^{8,9}$ In the present study, OVL induced a promotion of fibers expressing myosin heavy chain-2a in mdx mice, as previously reported. ${ }^{17}$ Pharmacological and genetic activation of calcineurin, AMP activated protein kinase, PGC- $1 \alpha$, and PPAR $\beta$ improves the force decrease after lengthening contractions in mdx mice, although the mechanisms are not yet well understood. ${ }^{55-57}$ Calcineurin, AMP activated protein kinase, PGC- $1 \alpha$, and PPAR signaling pathways also promote the formation of slow/oxidative fibers, and are likely responsible for the fast/glycolytic to slow/oxidative fiber transition induced by exercise. ${ }^{58,59}$ In the present study, several results suggest an increase in muscle oxidative energy metabolism after OVL in mdx mice, in agreement with previous studies in nondystrophic mice. ${ }^{22,31}$ Finally, an additional explanation is that the OVL-induced activation of Aktmammalian target of rapamycin signaling in $\mathrm{mdx}$ mice $^{17} \mathrm{can}$ contribute to the reduced force decrease. In fact, genetic activation of Akt has been previously reported to reduce the force decrease after lengthening contractions in $\mathrm{mdx}$ mice. $^{49}$

Whatever the exact mechanisms, the reduced fragility to contraction-induced damage of $\mathrm{mdx}$ mice in response to OVL could have important consequences because susceptibility to contraction-induced damage is likely the cause of the muscle- 
wasting syndrome in DMD (see below). This result suggests that it is not impossible that resistance training with high-force contractions could help to protect the muscle from damage in DMD patients, instead of worsening it, as was commonly thought. Several studies, including the present study, also support the notion that treatments (genetic Akt activation and $\beta$-adrenergic administration) making $\mathrm{mdx}$ muscles stronger protect them from lengthening contraction-induced damage. ${ }^{49,60}$ Together with a previous study, ${ }^{61}$ we have clearly demonstrated that both models of resistance and endurance exercise training can improve susceptibility to contractioninduced muscle damage in mdx mice and can even be as effective as sophisticated genetic therapeutic strategies aiming to restore dystrophin. ${ }^{36,62}$

\section{Beneficial Functional, Cellular, and Molecular Adaptations in Response to OVL}

Short- and long-term OVL also induced adaptations in $\mathrm{mdx}$ mice: marked gain in performance, hypertrophy, and a fast/ glycolytic to slow/oxidative fiber-type transition, confirming and extending our previous study. ${ }^{17}$ Consequently, if the same effects are observed in humans, this approach could be used to improve muscle function in DMD patients. In support of this possibility, a recent study has been shown that resistance training improves muscle strength and endurance in Becker muscular dystrophy patients. ${ }^{63}$ In the present study, the gain in performance results from muscle hypertrophy because specific maximal force remained unchanged in response to OVL in mdx mice. The hypertrophy might be explained by more fibers per cross section in response to short-term OVL, confirming several studies reporting hyperplasia in response to OVL. ${ }^{17,22,27-29}$ In response to longterm OVL, hypertrophy results from both hyperplasia and fiber hypertrophy in mdx mice. The promotion of slow/ oxidative fibers is also beneficial because it not only can improve fragility but also fatigue resistance. ${ }^{17}$

We observed no deterioration with time of these functional, cellular, and molecular adaptations. For example, absolute maximal force gain and muscle hypertrophy (increased muscle weight) in response to short- and longterm OVL were similar in $\mathrm{mdx}+\mathrm{OVL}(171 \%$ and $228 \%$, respectively) and $\mathrm{mdx}+$ OVL6m (151\% and $188 \%$, respectively). Because muscle adaptative capacity remained intact in the long-term in mdx mice, these findings also support the idea that OVL is not detrimental.

\section{No Depletion of Muscle Cell Progenitors}

Dystrophin deficiency increases the susceptibility to contraction-induced damage, initiates repeated degeneration/ regeneration cycles, and leads to muscle weakness and wasting. The progressive loss of function and depletion of muscle cell progenitors is believed to be the cause of the muscle wasting/weakness in DMD patients. Supporting this idea is the fact that depletion or loss of function of muscle cell progenitors (replicative senescence) results in severe muscular dystrophy and wasting in mouse. ${ }^{64,65}$ Therefore, there is a possibility that repeated high-force contractions and degeneration/regeneration cycles during a long period would deplete muscle cell progenitors in dystrophic muscle. Moreover, this risk might be markedly increased by the fact that these cells are essential not only for muscle repair ${ }^{32}$ but also for muscle remodeling in response to OVL, as shown in the present and previous studies. ${ }^{47,48}$ However, our results clearly do not support this hypothesis because the number of cells expressing Pax 7 was not reduced by long-term OVL in mdx mice.

\section{Conclusion}

Herein, we found that short-term OVL combined with wheel running and long-term OVL, an intensive model of resistance training, did not worsen dystrophic features in mdx mice. We also show that muscle regeneration did not compensate for the potentially deleterious effect of OVL. On the contrary, OVL was beneficial because it reduced a major dystrophic feature (ie, susceptibility to contraction-induced damage), increased absolute maximal force, induced hypertrophy, and triggered a promotion of slower/oxidative fibers. It will now be interesting to see if a similar approach could be used to reduced muscle weakness and protect the muscles of DMD patients from damage.

\section{Acknowledgments}

We thank Christel Gentil and Marie Thérèse Daher (University of Pierre et Marie Curie, Paris, France) and Nathalie Vadrot and Solenne Paiva (University of Paris Diderot, Paris, France).

\section{References}

1. Chan S, Head SI: The role of branched fibres in the pathogenesis of Duchenne muscular dystrophy. Exp Physiol 2011, 96:564-571

2. Lynch GS: Role of contraction-induced injury in the mechanisms of muscle damage in muscular dystrophy. Clin Exp Pharmacol Physiol 2004, 31:557-561

3. Whitehead NP, Yeung EW, Allen DG: Muscle damage in mdx (dystrophic) mice: role of calcium and reactive oxygen species. Clin Exp Pharmacol Physiol 2006, 33:657-662

4. Dellorusso C, Crawford RW, Chamberlain JS, Brooks SV: Tibialis anterior muscles in mdx mice are highly susceptible to contractioninduced injury. J Muscle Res Cell Motil 2001, 22:467-475

5. Hayes A, Williams DA: Contractile function and low-intensity ex ercise effects of old dystrophic (mdx) mice. Am J Physiol 1998, 274 : C1138-C1144

6. Lynch GS, Hinkle RT, Chamberlain JS, Brooks SV, Faulkner JA Force and power output of fast and slow skeletal muscles from mdx mice 6-28 months old. J Physiol 2001, 535:591-600

7. Pastoret C, Sebille A: Time course study of the isometric contractile properties of mdx mouse striated muscles. J Muscle Res Cell Motil $1993,14: 423-431$ 
8. Head S, Williams D, Stephenson G: Increased susceptibility of EDL muscles from mdx mice to damage induced by contraction with stretch. J Muscle Res Cell Motil 1994, 15:490-492

9. Moens P, Baatsen PH, Marechal G: Increased susceptibility of EDL muscles from mdx mice to damage induced by contractions with stretch. J Muscle Res Cell Motil 1993, 14:446-451

10. Burdi R, Rolland JF, Fraysse B, Litvinova K, Cozzoli A, Giannuzzi V, Liantonio A, Camerino GM, Sblendorio V, Capogrosso RF, Palmieri B, Andreetta F, Confalonieri P, De Benedictis L, Montagnani M, De Luca A: Multiple pathological events in exercised dystrophic mdx mice are targeted by pentoxifylline: outcome of a large array of in vivo and ex vivo tests. J Appl Physiol (1985) 2009, 106:1311-1324

11. Altamirano F, Valladares D, Henriquez-Olguin C, Casas M, Lopez JR, Allen PD, Jaimovich E: Nifedipine treatment reduces resting calcium concentration, oxidative and apoptotic gene expression, and improves muscle function in dystrophic mdx mice. PLoS One 2013, 8:e81222

12. Head SI: Branched fibres in old dystrophic mdx muscle are associated with mechanical weakening of the sarcolemma, abnormal Ca2+ transients and a breakdown of $\mathrm{Ca} 2+$ homeostasis during fatigue. Exp Physiol 2010, 95:641-656

13. Allen DG, Gervasio OL, Yeung EW, Whitehead NP: Calcium and the damage pathways in muscular dystrophy. Can J Physiol Pharmacol 2010, 88:83-91

14. Lovering RM, Brooks SV: Eccentric exercise in aging and diseased skeletal muscle: good or bad? J Appl Physiol (1985) 2013, 116: 1439-1445

15. Markert CD, Ambrosio F, Call JA, Grange RW: Exercise and Duchenne muscular dystrophy: toward evidence-based exercise prescription. Muscle Nerve 2011, 43:464-478

16. Petrof BJ: The molecular basis of activity-induced muscle injury in Duchenne muscular dystrophy. Mol Cell Biochem 1998, 179:111-123

17. Joanne P, Hourde C, Ochala J, Cauderan Y, Medja F, Vignaud A, Mouisel E, Hadj-Said W, Arandel L, Garcia L, Goyenvalle A, Mounier R, Zibroba D, Sakamato K, Butler-Browne G, Agbulut O, Ferry A: Impaired adaptive response to mechanical overloading in dystrophic skeletal muscle. PLoS One 2012, 7:e35346

18. Dick J, Vrbova G: Progressive deterioration of muscles in $\mathrm{mdx}$ mice induced by overload. Clin Sci (Lond) 1993, 84:145-150

19. Baldwin KM, Valdez V, Herrick RE, MacIntosh AM, Roy RR: Biochemical properties of overloaded fast-twitch skeletal muscle. J Appl Physiol 1982, 52:467-472

20. Bodine SC, Baar K: Analysis of skeletal muscle hypertrophy in models of increased loading. Methods Mol Biol 2012, 798:213-229

21. Booth FW, Thomason DB: Molecular and cellular adaptation of muscle in response to exercise: perspectives of various models. Physiol Rev 1991, 71:541-585

22. Ianuzzo CD, Gollnick PD, Armstrong RB: Compensatory adaptations of skeletal muscle fiber types to a long-term functional overload. Life Sci 1976, 19:1517-1523

23. Roy RR, Edgerton VR: Response of mouse plantaris muscle to functional overload: comparison with rat and cat. Comp Biochem Physiol A Physiol 1995, 111:569-575

24. Klitgaard $\mathrm{H}$ : A model for quantitative strength training of hindlimb muscles of the rat. J Appl Physiol 1988, 64:1740-1745

25. Lac G, Cavalie H: A rat model of progressive isometric strength training. Arch Physiol Biochem 1999, 107:144-151

26. Willems ME, Stauber WT: Effect of resistance training on muscle fatigue and recovery in intact rats. Med Sci Sports Exerc 2000, 32:1887-1893

27. Goodman CA, Frey JW, Mabrey DM, Jacobs BL, Lincoln HC, You JS, Hornberger TA: The role of skeletal muscle mTOR in the regulation of mechanical load-induced growth. J Physiol 2011, 589:5485-5501

28. McCarthy JJ, Mula J, Miyazaki M, Erfani R, Garrison K, Farooqui AB, Srikuea R, Lawson BA, Grimes B, Keller C, Van Zant G, Campbell KS, Esser KA, Dupont-Versteegden EE, Peterson CA: Effective fiber hypertrophy in satellite cell-depleted skeletal muscle. Development 2011, 138:3657-3666
29. Parsons SA, Millay DP, Wilkins BJ, Bueno OF, Tsika GL, Neilson JR, Liberatore CM, Yutzey KE, Crabtree GR, Tsika RW, Molkentin JD: Genetic loss of calcineurin blocks mechanical overload-induced skeletal muscle fiber type switching but not hypertrophy. J Biol Chem 2004, 279:26192-26200

30. Dunn SE, Burns JL, Michel RN: Calcineurin is required for skeletal muscle hypertrophy. J Biol Chem 1999, 274:21908-21912

31. Dunn SE, Michel RN: Coordinated expression of myosin heavy chain isoforms and metabolic enzymes within overloaded rat muscle fibers. Am J Physiol 1997, 273:C371-C383

32. Sambasivan R, Yao R, Kissenpfennig A, Van Wittenberghe L, Paldi A, Gayraud-Morel B, Guenou H, Malissen B, Tajbakhsh S, Galy A: Pax7-expressing satellite cells are indispensable for adult skeletal muscle regeneration. Development 2011, 138: $3647-3656$

33. Heslop L, Morgan JE, Partridge TA: Evidence for a myogenic stem cell that is exhausted in dystrophic muscle. J Cell Sci 2000, 113(Pt 12):2299-2308

34. Hamilton DL, Philp A, MacKenzie MG, Baar K: A limited role for $\mathrm{PI}(3,4,5) \mathrm{P} 3$ regulation in controlling skeletal muscle mass in response to resistance exercise. PLoS One 2010, 5:e11624

35. Rosenblatt JD, Parry DJ: Adaptation of rat extensor digitorum longus muscle to gamma irradiation and overload. Pflugers Arch 1993, 423: 255-264

36. Hoogaars WM, Mouisel E, Pasternack A, Hulmi JJ, Relizani K, Schuelke M, Schirwis E, Garcia L, Ritvos O, Ferry A, t Hoen PA, Amthor H: Combined effect of AAV-U7-induced dystrophin exon skipping and soluble activin type IIB receptor in mdx mice. Hum Gene Ther 2012, 23:1269-1279

37. Hourde C, Joanne P, Noirez P, Agbulut O, Butler-Browne G, Ferry A: Protective effect of female gender-related factors on muscle force-generating capacity and fragility in the dystrophic mdx mouse. Muscle Nerve 2013, 48:68-75

38. Fraysse B, Desaphy JF, Rolland JF, Pierno S, Liantonio A, Giannuzzi V, Camerino C, Didonna MP, Cocchi D, De Luca A, Conte Camerino D: Fiber type-related changes in rat skeletal muscle calcium homeostasis during aging and restoration by growth hormone. Neurobiol Dis 2006, 21:372-380

39. Joanne P, Chourbagi O, Hourde C, Ferry A, Butler-Browne G, Vicart P, Dumonceaux J, Agbulut O: Viral-mediated expression of desmin mutants to create mouse models of myofibrillar myopathy. Skelet Muscle 2013, 3:4

40. Launay T, Noirez P, Butler-Browne G, Agbulut O: Expression of slow myosin heavy chain during muscle regeneration is not always dependent on muscle innervation and calcineurin phosphatase activity. Am J Physiol Regul Integr Comp Physiol 2006, 290: R1508-R1514

41. Butler-Browne GS, Whalen RG: Myosin isozyme transitions occurring during the postnatal development of the rat soleus muscle. Dev Biol 1984, 102:324-334

42. Noirez P, Ferry A: Effect of anabolic/androgenic steroids on myosin heavy chain expression in hindlimb muscles of male rats. Eur J Appl Physiol 2000, 81:155-158

43. Agbulut O, Li Z, Mouly V, Butler-Browne GS: Analysis of skeletal and cardiac muscle from desmin knock-out and normal mice by high resolution separation of myosin heavy-chain isoforms. Biol Cell 1996, 88:131-135

44. Agbulut O, Noirez P, Beaumont F, Butler-Browne G: Myosin heavy chain isoforms in postnatal muscle development of mice. Biol Cell 2003, 95:399-406

45. Schirwis E, Agbulut O, Vadrot N, Mouisel E, Hourde C, Bonnieu A, Butler-Browne G, Amthor H, Ferry A: The beneficial effect of myostatin deficiency on maximal muscle force and power is attenuated with age. Exp Gerontol 2013, 48:183-190

46. Ye J, Coulouris G, Zaretskaya I, Cutcutache I, Rozen S, Madden TL: Primer-BLAST: A tool to design target-specific primers for polymerase chain reaction. BMC Bioinformatics 2012, 13:134 
47. Adams GR, Caiozzo VJ, Haddad F, Baldwin KM: Cellular and molecular responses to increased skeletal muscle loading after irradiation. Am J Physiol Cell Physiol 2002, 283:C1182-C1195

48. Rosenblatt JD, Yong D, Parry DJ: Satellite cell activity is required for hypertrophy of overloaded adult rat muscle. Muscle Nerve 1994, 17: 608-613

49. Blaauw B, Mammucari C, Toniolo L, Agatea L, Abraham R, Sandri M, Reggiani C, Schiaffino S: Akt activation prevents the force drop induced by eccentric contractions in dystrophin-deficient skeletal muscle. Hum Mol Genet 2008, 17:3686-3696

50. Brooks SV: Rapid recovery following contraction-induced injury to in situ skeletal muscles in mdx mice. J Muscle Res Cell Motil 1998, 19:179-187

51. Deconinck N, Rafael JA, Beckers-Bleukx G, Kahn D, Deconinck AE, Davies KE, Gillis JM: Consequences of the combined deficiency in dystrophin and utrophin on the mechanical properties and myosin composition of some limb and respiratory muscles of the mouse. Neuromuscul Disord 1998, 8:362-370

52. Tinsley J, Deconinck N, Fisher R, Kahn D, Phelps S, Gillis JM, Davies K: Expression of full-length utrophin prevents muscular dystrophy in mdx mice. Nat Med 1998, 4:1441-1444

53. Chakkalakal JV, Stocksley MA, Harrison MA, Angus LM, DeschenesFurry J, St-Pierre S, Megeney LA, Chin ER, Michel RN, Jasmin BJ: Expression of utrophin A mRNA correlates with the oxidative capacity of skeletal muscle fiber types and is regulated by calcineurin/NFAT signaling. Proc Natl Acad Sci U S A 2003, 100:7791-7796

54. Ljubicic V, Burt M, Jasmin BJ: The therapeutic potential of skeletal muscle plasticity in Duchenne muscular dystrophy: phenotypic modifiers as pharmacologic targets. FASEB J 2014, 28:548-568

55. Miura P, Chakkalakal JV, Boudreault L, Belanger G, Hebert RL, Renaud JM, Jasmin BJ: Pharmacological activation of PPARbeta/ delta stimulates utrophin A expression in skeletal muscle fibers and restores sarcolemmal integrity in mature mdx mice. Hum Mol Genet 2009, 18:4640-4649

56. Selsby JT, Morine KJ, Pendrak K, Barton ER, Sweeney HL: Rescue of dystrophic skeletal muscle by PGC-1alpha involves a fast to slow fiber type shift in the mdx mouse. PLoS One 2012, 7:e30063
57. Stupka N, Plant DR, Schertzer JD, Emerson TM, Bassel-Duby R, Olson EN, Lynch GS: Activated calcineurin ameliorates contractioninduced injury to skeletal muscles of mdx dystrophic mice. J Physiol 2006, 575:645-656

58. Gundersen K: Excitation-transcription coupling in skeletal muscle: the molecular pathways of exercise. Biol Rev Camb Philos Soc 2010, $86: 564-600$

59. Schiaffino S, Sandri M, Murgia M: Activity-dependent signaling pathways controlling muscle diversity and plasticity. Physiology (Bethesda) 2007, 22:269-278

60. Gehrig SM, Koopman R, Naim T, Tjoakarfa C, Lynch GS: Making fast-twitch dystrophic muscles bigger protects them from contraction injury and attenuates the dystrophic pathology. Am J Pathol 2010, 176:29-33

61. Hourde C, Joanne P, Medja F, Mougenot N, Jacquet A, Mouisel E, Pannerec A, Hatem S, Butler-Browne G, Agbulut O, Ferry A: Voluntary physical activity protects from susceptibility to skeletal muscle contraction-induced injury but worsens heart function in $\mathrm{mdx}$ mice. Am J Pathol 2013, 182:1509-1518

62. Koo T, Malerba A, Athanasopoulos T, Trollet C, Boldrin L, Ferry A, Popplewell L, Foster H, Foster K, Dickson G: Delivery of AAV2/9microdystrophin genes incorporating helix 1 of the coiled-coil motif in the C-terminal domain of dystrophin improves muscle pathology and restores the level of alpha1-syntrophin and alpha-dystrobrevin in skeletal muscles of mdx mice. Hum Gene Ther 2011, 22:1379-1388

63. Sveen ML, Andersen SP, Ingelsrud LH, Blichter S, Olsen NE, Jonck S, Krag TO, Vissing J: Resistance training in patients with limb-girdle and becker muscular dystrophies. Muscle Nerve 2013, 47: $163-169$

64. Didier N, Hourde C, Amthor H, Marazzi G, Sassoon D: Loss of a single allele for Ku80 leads to progenitor dysfunction and accelerated aging in skeletal muscle. EMBO Mol Med 2012, 4:910-923

65. Sacco A, Mourkioti F, Tran R, Choi J, Llewellyn M, Kraft P, Shkreli M, Delp S, Pomerantz JH, Artandi SE, Blau HM: Short telomeres and stem cell exhaustion model Duchenne muscular dystrophy in mdx/mTR mice. Cell 2010, 143:1059-1071 